\title{
The Chemical Composition and Biological Activities of Essential Oils from Zanthoxylum rhetsa Grown in Son La, Northwest Vietnam
}

\author{
Cao Bach Pham, ${ }^{1}$ Thi Inh Cam, ${ }^{1}$ Tuyen Tran Thi, ${ }^{1}$ Pham Minh Quan ${ }^{1 D},{ }^{1}$ Tran Quoc Toan, \\ Huu Nghi Do, ${ }^{1}$ Dinh Thi Thu Thuy, ${ }^{1}$ Thi Thuy Nguyen, ${ }^{1}$ Anh Vien Trinh,, \\ Thi Hong Minh Pham, ${ }^{1}$ Quoc Long Pham ${ }^{10}{ }^{1}$ Tran Thien Hien, ${ }^{3,4}$ \\ Dung Thuy Nguyen Pham $\mathbb{D}^{4,5}$ and Hong Van Nguyen Thi $\mathbb{D}^{1,6}$ \\ ${ }^{1}$ Institute of Natural Products Chemistry (INPC), Vietnam Academy of Science and Technology (VAST), \\ 18 Hoang Quoc Viet Cau Giay, Ha Noi, Vietnam \\ ${ }^{2}$ Hanoi Medical University, 01 Ton That Tung Đong Đa, Ha Noi, Vietnam \\ ${ }^{3}$ Institute of Environmental Sciences, Nguyen Tat Thanh University, Ho Chi Minh City 70000, Vietnam \\ ${ }^{4}$ Faculty of Environmental and Food Engineering, Nguyen Tat Thanh University, Ho Chi Minh City 70000, Vietnam \\ ${ }^{5}$ NTT Hi-Tech Institute, Nguyen Tat Thanh University, Ho Chi Minh City 70000, Vietnam \\ ${ }^{6}$ Graduate University of Sciences and Technology, Vietnam Academy of Science and Technology (VAST), \\ 18 Hoang Quoc Viet Cau Giay, Ha Noi, Vietnam
}

\begin{abstract}
Correspondence should be addressed to Dung Thuy Nguyen Pham; pntdung@ntt.edu.vn and Hong Van Nguyen Thi; nguyenthihongvan.inpc.vast@gmail.com
\end{abstract}

Received 8 March 2021; Accepted 29 June 2021; Published 12 July 2021

Academic Editor: Chunpeng Wan

Copyright (c) 2021 Cao Bach Pham et al. This is an open access article distributed under the Creative Commons Attribution License, which permits unrestricted use, distribution, and reproduction in any medium, provided the original work is properly cited.

\begin{abstract}
Essential oils (EOs) from the stem barks, leaf petioles, fruit petioles, fresh leaves, and fresh and dried fruits of Zanthoxylum rhetsa were extracted by hydrodistillation. The volatile compounds of the products were analyzed by gas chromatography (GC-FID) and gas chromatography/mass spectrometry (GC/MSD). Monoterpene hydrocarbons formed the predominant fraction of all six EO samples, of which sabinene is one of the major components (from $12.37 \%$ to $41.13 \%$ ). For the leaf petiole EO, limonene (25.01\%), sabinene (14.56\%), and linalool (12.63\%) are the major constituents, while the main constituents of fruit petiole EO were terpinolene (19.66\%), terpinen-4-ol (19.07\%), and sabinene (17.83\%). The major components of stem bark EO are terpinen-4-ol (18.23\%), sabinene (12.37\%), $\alpha$-phellandrene (7.34\%), $\beta$-phellandrene (6.32\%), and $\gamma$-terpinene (6.12\%), while sabinene (38.35\%), terpinen-4-ol (13.71\%), $\gamma$-terpinene (6.47\%), and limonene $(6.02 \%)$ are the major constituents of fresh leaf EO. For the EOs of dried fruits and fresh fruits, sabinene, terpinolene, limonene, and terpinen-4-ol are the major constituents. The essential oils were also tested for their cytotoxic and antimicrobial activities. The results revealed that six EOs at concentrations of $50 \mu \mathrm{g} / \mathrm{mL}$ exhibited inhibitory activity against at least one tested cancer cell line but were nontoxic on Vero normal cells. Most EOs showed moderate antimicrobial activity against $F$. oxysporum; however, there were no obvious activity against $B$. subtilis and $S$. aureus.
\end{abstract}

\section{Introduction}

Zanthoxylum rhetsa (Roxb.) DC (Z. rhetsa) is a flowering plant of the Rutaceae family found in India, Myanmar, Thailand, Lao, and Vietnam. The tree has a medium size (about 14-18 meter in height) with a straight body, thorny branches, and $10-15 \mathrm{~cm}$ lanceolate leaves. The Z. rhetsa flowering season is between June and July with clusters of gray-white flowers and fruiting in October and November $[1,2]$. Z. rhetsa is an indigenous plant in the northwest of 
Vietnam, where the Son La province accounted for $71 \%$ of the total production [3]. Fruit and seed powders of $Z$. rhetsa are used as spices for cooking or for meat preservation by ethnic minorities such as Thai and H'Mong. Moreover, the plant is also used as traditional treatment for toothache, abdominal and stomach pain, and improving digestion $[3,4]$.

The chemical composition of the essential oil of $Z$. rhetsa grown in India and Thailand has been reported. For instance, the seed EO of $Z$. rhetsa grown in Kerala (South India) contained mostly monoterpenes [5], while sesquiterpenes were predominant in the leaf EO, with the major components include caryophyllene oxide, $\beta$-caryophyllene, $\beta$-copaene, and spathulenol [6]. The phytochemical profile of the seed EO, i.e., the presence of sabinene, $\alpha$-pinene, $\alpha$-terpinene, $\beta$-pinene, $\gamma$-terpinene, myrcene, terpinolene, and limonene, was also varied according to the $\mathrm{pH}$ of environment [7]. Meanwhile, the seed coat of $Z$. rhetsa collected from Senapati (the northeast of India) mainly consisted of terpinen-4-ol (32.1\%), $\alpha$-terpineol $(8.2 \%)$, sabinene $(8.1 \%)$, along with $\beta$-phellandrene and 2 -undecanone at $7.4 \%$ and $7.1 \%$, respectively [8]. However, in some areas of Thailand such as Nan and Chiang Rai, the dried and the fresh fruits of $Z$. rhetsa contained different levels of limonene $\quad(27.10 \%-59.68 \%), \quad \beta$-phellandrene $\quad(10.88 \%-$ $19.40 \%)$, and sabinene $(25.03 \%-31.21 \%)$ [9]. On the other hand, sabinene $(22.51 \%)$ and terpinene-4-ol (32.33\%) were the major components of the EO extracted from fresh fruits of $Z$. rhetsa collected from Phayao (Thailand) [10].

Numerous studies have reported the interesting biological activities of $Z$. rhetsa EOs. The fresh fruit EO of $Z$. rhetsa grown in Phayao, Thailand, has showed antiproliferative activity against breast cancer cells, and thus it was proposed as a potential food preservative and anticancer drug [10]. Meanwhile, terpinen-4-ol, which is the main constituent of pericarp EO, has the ability to inhibit the stress and diseases related to stomach and intestines [11].

In this paper, the EOs obtained from the different parts of $Z$. rhetsa (e.g., stem bark, leaf petiole, fruit petiole, fresh leaves, and fresh and dried fruit) grown in Son La, Northwest Vietnam, were extracted by hydrodistillation and its chemical composition was analyzed by GS/MS. In addition, these EOs have been evaluated for their biological activities, which included antibacterial and antiproliferative activities.

\section{Materials and Methods}

2.1. Materials. The stem bark, leaf petiole, fruit petiole, leaves, and fruits of $Z$. rhetsa were collected from the Thuan Chau district, Son La province, Vietnam. Plant identification was performed by Dr. Nguyen Quoc Binh, the Vietnam Museum of Nature (VMN), Vietnam Academy of Science and Technology (VAST). All the plant parts were washed with tap water three times, air-dried at room temperature, and then stored in a refrigerator. $500 \mathrm{~g}$ of each fresh sample of stem bark, leaf petiole, fruit petiole, and leaves was chopped into pieces, and $200 \mathrm{~g}$ of fresh fruits was crushed as samples for EO isolation. $500 \mathrm{~g}$ of fresh fruits was dried at room temperature and then were ground as samples for EO isolation.
2.2. Isolation of Essential Oils. The oil extraction was performed by hydrodistillation in the Clevenger-type apparatus for $3 \mathrm{~h}$ at normal pressure. The collected EOs were dehydrated with anhydrous sodium sulfate, weighted, and refrigerated until analysis. The samples were labeled as SB: stem bark; LP: leaf petiole; FP: fruit petiole; FL: fresh leaves; DF: dried fruit; and FF: fresh fruit.

2.3. GC-MSD and GC-FID Analysis. The chemical compositions of EOs were analyzed by Agilent 7890A gas chromatography (GC) equipped with an MSD Agilent 5975C detector and a HP-5MS column $(60 \mathrm{~m} \times 0.25 \mathrm{~mm}, 0.25 \mu \mathrm{m}$ film thickness) (Agilent Technologies, CA, USA). Other conditions were set as follows: $250^{\circ} \mathrm{C}$ as injector temperature, helium as the carrier gas, $1 \mathrm{~mL} \cdot \mathrm{min}^{-1}$ as flow rate, and temperature program from $60^{\circ} \mathrm{C}$ to $240^{\circ} \mathrm{C}\left(4^{\circ} \mathrm{C} / \mathrm{min}\right)$. The split ratio was $100: 1$, and the injection volume of EO was $1 \mu \mathrm{L}$. The MSD full-scan mode was applied under $70 \mathrm{eV}$ of ionization voltage, $40 \mathrm{~mA}$ of emission current, and 35-450 amu of acquisition scan mass range.

The constituents were identified by comparing their mass spectrum with the W09N08 libraries and NIST Chemistry WebBook (http://webbook.nist.gov/chemistry/) database. The retention indices (RIs) of EO components were calculated by MassFinder 4.0 software base on homologous $n$-alkanes with same conditions. The relative content of each phytochemical component was estimated based on the GC-FID peak area with same conditions.

2.4. Antimicrobial Assays. The antimicrobial assays were performed by using four bacterial and two fungal strains purchased from American Type Culture Collection (ATCC, Manassas, VA, USA), including Escherichia coli ATCC 8739, Bacillus subtilis ATCC 27212, Pseudomonas aeruginosa ATCC 25923, Staphylococcus aureus ATCC 12222, Aspergillus niger ATCC 9763, and Fusarium oxysporum ATCC 48112. The culture of the microorganisms with an inoculum size of about $10^{5}$ colony-forming units (CFU) per $\mathrm{mL}$ was prepared and loaded into 96-well microplates. Samples at different concentrations $(50-200 \mu \mathrm{g} / \mathrm{mL})$ were prepared by dissolving in $5 \%$ DMSO, then loaded into the plates, and incubated at $37^{\circ} \mathrm{C}$ for $24 \mathrm{~h}$. Gentamycin $(16 \mathrm{IU} / \mathrm{mg}, 8 \mathrm{IU} / \mathrm{mg}$, and $4 \mathrm{IU} / \mathrm{mg})$, doxycycline $(0.4 \mathrm{IU} / \mathrm{mg}, 0.2 \mathrm{IU} / \mathrm{mg}$, and $0.1 \mathrm{IU} / \mathrm{mg}$ ), and nystatin (12 IU/mg, $6 \mathrm{IU} / \mathrm{mg}$, and $3 \mathrm{IU} / \mathrm{mg}$ ) (Merck KGaA, Darmstadt, Germany) were used as positive references. 5\% DMSO was used as the negative control [12].

2.5. Cell Proliferation Assays. Five human cancer cell lines (e.g., HeLa, Hep-G2, A-549, MCF-7, and HGC-27) and a normal cell line Vero were obtained from ATCC and maintained in suitable media (RPMI 1640, MEM, DMEM; Sigma Aldrich Inc., Saint. Louis, MO, USA) at $37^{\circ} \mathrm{C}$ in $5 \%$ $\mathrm{CO}_{2}$. MTT assay was performed to investigate the viability of cancer cells $[13,14]$. Dilution was performed in a 96-well microplate to obtain a density of $5 \times 10^{4}$ cells per well. The samples $(0.63-50 \mu \mathrm{g} / \mathrm{mL})$, DMSO as the negative control (Merck KGaA) and ellipticine as the positive control (Merck 
$\mathrm{KGaA}$ ), were added to the wells and incubated at $37^{\circ} \mathrm{C}$ for $48 \mathrm{~h}$. A total of $20 \mu \mathrm{L}$ of MTT (Sigma-Aldrich, Saint. Louis, MO, USA) was then added, and incubation was continued for another $4 \mathrm{~h}$ at $37^{\circ} \mathrm{C}$. Absorbance was measured at $540 /$ $720 \mathrm{~nm}$ using a Spark multimode reader (Tecan, Männedorf, Switzerland). All experiments were performed in triplicate. The growth inhibition (\%) was calculated by using the formula: Inhibition rate $(\%)=\left(1-\mathrm{OD}_{\text {sampl }} / \mathrm{OD}_{\text {con }}\right) \times 100 \%$, where $\mathrm{OD}_{\text {sampl }}$ and $\mathrm{OD}_{\text {con }}$ are the optical densities of the sample groups and control, respectively.

\section{Results and Discussion}

3.1. Chemical Composition of Z. rhetsa Essential Oils. Essential oils from the different parts of $Z$. rhetsa were obtained by hydrodistillation and analyzed for phytochemical profile by GC-MSD/GC-FID. The results are shown in Table 1 and Figure 1.

3.1.1. Stem Bark EO. Fifty-one constituents were detected, which comprised $98.85 \%$ of the total oil (Figure 1(a)). The major components were terpinen-4-ol (18.23\%), sabinene (12.37\%), $\alpha$-phellandrene (7.34\%), $\beta$-phellandrene (6.32\%), and $\gamma$-terpinene $(6.12 \%)$. The EO was rich in monoterpene hydrocarbons $(52.17 \%)$ followed by oxygenated monoterpenes $(24.41 \%)$, sesquiterpene hydrocarbons (12.61\%), oxygenated sesquiterpenes (6.93\%), and aliphatic ketones (2.77\%).

3.1.2. Leaf Petiole EO. The chemical constituents accounted for $99.69 \%$ of the total oil (Figure 1(b)). Monoterpene hydrocarbons were the most abundant in leaf EOs, with limonene being the major compound (25.01\%). Oxygenated monoterpenes represented $24.07 \%$ of the EO, with linalool $(12.63 \%)$ as the major compound. A minor quantity $(2.7 \%)$ of sesquiterpene hydrocarbons was represented with $\beta$-caryophyllene (1.23\%) as the major compound. Oxygenated sesquiterpenes represented $1.11 \%$ of the oil.

3.1.3. Fruit Petiole EO. The chemical constituents accounted for $99.69 \%$ of the total oil (Figure 1(c)). Monoterpene hydrocarbons, which are mainly terpinolene and sabinene, formed the predominant fraction (54.66\%) followed by oxygenated monoterpene (41.64\%), sesquiterpene hydrocarbons $(2.71 \%)$, and oxygenated sesquiterpenes $(0.29 \%)$. The others represented $0.18 \%$ of the total oil.

3.1.4. Fresh Leaf EO. The chemical constituents accounted for $99.57 \%$ of the total oil (Figure 1(d)). Monoterpene hydrocarbons were the most abundant (74.64\%) with sabinene, $\gamma$-terpinene, limonene, and $\alpha$-pinene. Terpinen-4-ol $(13.71 \%)$ was the major compound of the oxygenated monoterpene fraction (19.01\%). A minor quantity of sesquiterpene hydrocarbons was found (3.72\%) with $\beta$-caryophyllene $(1.53 \%)$ as the major constituent. Oxygenated sesquiterpenes and the others represented $0.29 \%$ and $1.92 \%$ of the EO, respectively. This result was different from the study of Jirovetz et al., where sesquiterpenes and monoterpenes were presented with the quantities of $38.6 \%$ and $2.2 \%$, respectively [6].

3.1.5. Fresh Fruit and Dried Fruit EOs. A total of 23 components from fresh fruit $\mathrm{EO}(\mathrm{FF})$ and 26 components from dried fruit EO (DF) were identified, accounting for $99.99 \%$ (Figures 1(e) and 1(f)). The monoterpene hydrocarbon fractions were enriched in the two EOs $(83.71 \%$ and $84.28 \%$, respectively), with sabinene $(41.13 \%$ and $32.88 \%$, respectively), terpinolene $(27.05 \%$ and $30.37 \%$, respectively), and limonene $(7.84 \%$ and $8.29 \%$, respectively). Next, the oxygenated monoterpene fractions were $15.04 \%$ and $14.74 \%$ for FF and DF, respectively. The major components of this fraction were $\alpha$-terpineol $(6.08 \%, 3.27 \%)$ and terpinen-4-ol $(5.35 \%, 7.73 \%)$, respectively. In comparison with another result of chemical constituents of fresh fruit EO collected from the Mai Chau district of the Hoa Binh province in Vietnam, there were 24 components found, in which benzene, benzaldehyde-4-methoxy, 1-methoxy-4 (1-propenyl), 1-butanon, 1-(4-hydroxyphenyl), benzene-methanol, and alpha-ethyl-4-methoxy were the main components [18].

There are nineteen common compounds present in all six essential oil samples, including sabinene, limonene, terpinolene, terpinen-4-ol, $\alpha$-terpineol, $\gamma$-terpinene, $\alpha$-terpinene, linalool, trans- $\beta$-ocimene, myrcene, $\alpha$-pinene, $\beta$-phellandrene, $\alpha$-thujene, trans-sabinene hydrate, cissabinene hydrate, trans-p-menth-2-en-1-ol, cis-p-menth-2en-1-ol, geranyl acetate, and germacrene D. In these common compounds, sabinene is present in high content in all six EOs (from $12.37 \%$ to $41.13 \%$ ) followed by terpinen-4-ol (from $5.35 \%$ to $19.07 \%$ ) and limonene (from $4.18 \%$ to $25.01 \%)$. Meanwhile, there are some compounds present in all six EO samples, but all in low content (less than 5\%), such as $\alpha$-terpineol, $\alpha$-thujene, myrcene, $\alpha$-terpinene, trans$\beta$-ocimene, cis-sabinene hydrate, trans-sabinene hydrate, cis-p-menth-2-en-1-ol, trans-p-menth-2-en-1-ol, geranyl acetate, and germacrene D. However, there is a large difference in the content of some compounds in six EO samples, such as terpinolene is present in high content in dried fruits, fresh fruits, fruit petioles, and leaf petioles (30.37\%, 27.05\%, 19.66\%, and 6.86\%, respectively) but with low content in fresh leaves and stem barks $(1.91 \%$ and $1.57 \%$, respectively); linalool is present in relatively high content in leaf petioles and fruit petioles $(12.63 \%$ and $11.64 \%$, respectively), but it is only present in low content in fresh leaves, fresh fruits, stem barks, and dried fruits $(1.80 \%, 1.71 \%, 1.61 \%$, and $0.84 \%$, respectively); $\alpha$-pinene presents with $7.00 \%$ in leaf petioles and $5.62 \%$ in fresh leaves, but it has only trace content in the samples of dried fruits $(0.67 \%)$ and fresh fruits $(0.54 \%)$. These differences are displayed in Figure 2.

Some compounds are only present in a certain EO and therefore are assumed to have properties specific to a certain EO: $\delta$-3-carene, 2 -undecanone, $\alpha$-cubebene, $\beta$-cubebene, $\alpha$-copaene, cis- $\beta$-elemene, $\beta$-selinene, elemol, spathulenol, 1 -epi-cubenol, epi- $\alpha$-cadinol, $\alpha$-muurolol, and neo- 
TABle 1: Phytochemical profile of EOs from the different parts of Z. rhetsa.

\begin{tabular}{|c|c|c|c|c|c|c|c|c|}
\hline \multirow{2}{*}{ Compound name } & \multirow{2}{*}{$\mathrm{RI}^{a / b}$} & \multirow{2}{*}{ RI } & \multicolumn{6}{|c|}{ Percentage } \\
\hline & & & SB & LP & FP & FL & DF & FF \\
\hline (Z)-Hex-3-en-1-ol & 854 & 851 & - & - & - & 0.45 & - & - \\
\hline (Z)-Hex-2-en-1-ol & 855 & 860 & - & - & - & 1.06 & - & - \\
\hline$n$-Hexanol & 871 & 862 & - & - & - & 0.41 & - & - \\
\hline$\alpha$-Thujene & 930 & 930 & 0.75 & 0.42 & 0.27 & 1.14 & 0.61 & 0.35 \\
\hline$\alpha$-Pinene & 939 & 939 & 2.09 & 7.00 & 1.07 & 5.62 & 0.67 & 0.54 \\
\hline Sabinene & 975 & 978 & 12.37 & 14.56 & 17.83 & 38.35 & 33.71 & 41.13 \\
\hline$\beta$-Pinene & 979 & 984 & 0.14 & 0.26 & - & 1.12 & - & - \\
\hline Myrcene & 991 & 991 & 1.89 & 1.87 & 1.17 & 2.00 & 2.02 & 1.76 \\
\hline$n$-Octanal & 999 & 1003 & - & - & - & - & - & 0.26 \\
\hline$\alpha$-Phellandrene & 1003 & 1010 & 7.34 & 2.74 & 0.10 & 2.11 & 0.11 & - \\
\hline$\delta$-3-Carene & 1011 & 1016 & 0.15 & - & - & - & - & - \\
\hline$\alpha$-Terpinene & 1017 & 1021 & 3.63 & 1.90 & 2.23 & 3.68 & 2.03 & 1.12 \\
\hline$o$-Cymene & 1026 & 1029 & 0.71 & 0.42 & 0.39 & 0.66 & 0.23 & - \\
\hline Limonene & 1029 & 1034 & 4.18 & 25.01 & 4.44 & 6.02 & 8.29 & 7.30 \\
\hline$\beta$-Phellandrene & 1030 & 1035 & 6.32 & 2.08 & 0.26 & 2.53 & 0.35 & 0.26 \\
\hline cis- $\beta$-Ocimene & 1037 & 1037 & 0.89 & 0.51 & 0.12 & 0.20 & - & - \\
\hline trans- $\beta$-Ocimene & 1050 & 1048 & 4.02 & 5.05 & 2.69 & 2.83 & 2.55 & 2.37 \\
\hline$\gamma$-Terpinene & 1060 & 1063 & 6.12 & 3.16 & 4.43 & 6.47 & 3.34 & 1.83 \\
\hline$n$-Octanol & 1068 & 1068 & - & - & - & - & - & 0.13 \\
\hline cis-Sabinene hydrate & 1070 & 1072 & 0.38 & 0.24 & 0.79 & 0.49 & 0.65 & 0.54 \\
\hline Terpinolene & 1089 & 1094 & 1.57 & 6.86 & 19.66 & 1.91 & 30.37 & 27.05 \\
\hline Linalool & 1097 & 1101 & 1.61 & 12.63 & 11.64 & 1.80 & 0.84 & 1.71 \\
\hline trans-Sabinene hydrate & 1098 & 1104 & 0.35 & 0.25 & 0.74 & 0.43 & 0.44 & 0.30 \\
\hline trans-4,8-Dimethylnona-1,3,7-triene & 1103 & 1117 & - & - & 0.18 & - & - & - \\
\hline cis-p-Menth-2-en-1-ol & 1122 & 1128 & 1.08 & 0.49 & 1.14 & 0.75 & 0.42 & 0.33 \\
\hline trans- $p$-Menth-2-en-1-ol & 1141 & 1145 & 0.73 & 0.34 & 0.83 & 0.53 & 0.31 & 0.22 \\
\hline Terpinen-4-ol & 1177 & 1186 & 18.23 & 7.78 & 19.07 & 13.71 & 7.73 & 5.35 \\
\hline p-Cymen-8-ol & 1183 & 1190 & - & - & 0.17 & - & 0.32 & - \\
\hline$\alpha$-Terpineol & 1189 & 1197 & 0.89 & 1.55 & 5.35 & 0.70 & 3.27 & 6.08 \\
\hline cis-Piperitol & 1196 & 1203 & 0.26 & 0.13 & 0.28 & 0.18 & - & - \\
\hline Decanal & 1202 & 1206 & - & - & - & - & 0.34 & 0.40 \\
\hline Octyl acetate & 1214 & 1210 & - & - & - & - & 0.23 & 0.22 \\
\hline trans-Piperitol & 1208 & 1214 & 0.41 & 0.17 & 0.46 & 0.28 & 0.13 & - \\
\hline Nerol & 1230 & 1231 & 0.12 & - & 0.25 & - & - & - \\
\hline Geraniol & 1253 & 1255 & 0.19 & 0.22 & 0.58 & - & - & - \\
\hline 2-Undecanone & 1294 & 1294 & 2.77 & - & - & - & - & - \\
\hline$\alpha$-Cubebene & 1351 & 1360 & 0.16 & - & - & - & - & - \\
\hline Geranyl acetate & 1381 & 1383 & 0.16 & 0.27 & 0.34 & 0.14 & 0.63 & 0.51 \\
\hline$\alpha$-Copaene & 1377 & 1389 & 0.36 & - & - & - & - & - \\
\hline$\beta$-Cubebene & 1388 & 1401 & 0.21 & - & - & - & - & - \\
\hline cis- $\beta$-Elemene & 1391 & 1403 & 0.21 & - & - & - & - & - \\
\hline $\begin{array}{l}\text { (E)-Caryophyllene } \\
\text { ( } \beta \text {-Caryophyllene) }\end{array}$ & 1419 & 1437 & 3.42 & 1.23 & 1.01 & 1.53 & 0.11 & - \\
\hline$\alpha$-Humulene & 1455 & 1471 & 0.67 & 0.21 & 0.19 & 0.25 & - & - \\
\hline$\beta$-Chamigrene & 1478 & 1489 & 0.38 & - & - & - & - & - \\
\hline Germacrene D & 1485 & 1498 & 3.46 & 0.65 & 0.76 & 0.88 & 0.27 & 0.24 \\
\hline$\beta$-Selinene & 1490 & 1503 & 0.38 & - & - & - & - & - \\
\hline$(E, E)-\alpha$-Farnesene & 1506 & 1512 & - & - & - & 0.51 & - & - \\
\hline Bicyclogermacrene & 1500 & 1513 & 2.28 & 0.40 & 0.32 & 0.36 & - & - \\
\hline$\gamma$-Cadinene & 1514 & 1530 & 0.11 & - & - & - & - & - \\
\hline$\delta$-Cadinene & 1523 & 1536 & 0.97 & 0.21 & 0.12 & 0.19 & - & - \\
\hline Elemol & 1550 & 1562 & 0.58 & - & - & - & - & - \\
\hline Spathulenol & 1578 & 1595 & 0.38 & - & - & - & - & - \\
\hline Viridiflorol & 1593 & 1603 & 0.45 & 0.15 & - & - & - & - \\
\hline Guaiol (=champacol) & 1601 & 1613 & 0.55 & 0.23 & 0.31 & - & - & - \\
\hline 1-epi-Cubenol & 1629 & 1645 & 0.17 & - & - & - & - & - \\
\hline epi- $\alpha$-Cadinol (=tau-cadinol) & 1640 & 1657 & 0.26 & - & - & - & - & - \\
\hline epi- $\alpha$-Muurolol (=tau-muurolol) & 1642 & 1658 & 0.96 & 0.22 & - & 0.11 & - & - \\
\hline$\alpha$-Muurolol $(=\delta$-cadinol $)$ & 1646 & 1661 & 0.29 & - & - & - & - & - \\
\hline$\alpha$-Cadinol & 1654 & 1671 & 1.12 & 0.40 & 0.28 & 0.18 & - & - \\
\hline
\end{tabular}


TABle 1: Continued.

\begin{tabular}{|c|c|c|c|c|c|c|c|c|}
\hline \multirow{2}{*}{ Compound name } & \multirow{2}{*}{$\mathrm{RI}^{a / b}$} & \multirow{2}{*}{ RI } & \multicolumn{6}{|c|}{ Percentage } \\
\hline & & & SB & LP & FP & FL & DF & $\mathrm{FF}$ \\
\hline Neointermedeol & 1660 & 1674 & 1.93 & - & - & - & - & - \\
\hline Bulnesol & 1672 & 1685 & 0.24 & 0.11 & 0.23 & - & - & - \\
\hline Total & & & 98.85 & 99.69 & 99.69 & 99.57 & 99.99 & 99.99 \\
\hline Monoterpene hydrocarbons & & & 52.17 & 71.84 & 54.66 & 74.64 & 84.28 & 83.71 \\
\hline Oxygenated monoterpenes & & & 24.41 & 24.07 & 41.64 & 19.01 & 14.74 & 15.04 \\
\hline Sesquiterpene hydrocarbons & & & 12.61 & 2.7 & 2.71 & 3.72 & 0.38 & 0.24 \\
\hline Oxygenated sesquiterpenes & & & 6.93 & 1.11 & 0.51 & 0.29 & - & - \\
\hline Aliphatic ketones & & & 2.77 & - & - & - & - & - \\
\hline Others & & & - & - & 0.18 & 1.92 & 0.57 & 1.01 \\
\hline
\end{tabular}

$\mathrm{RI}^{\mathrm{a} / \mathrm{b}}$ : retention index compared between software predictions [15-17]; SB: stem bark; LP: leaf petiole; FP: fruit petiole; FL: fresh leave; DF: dried fruit; FF: fresh fruit.

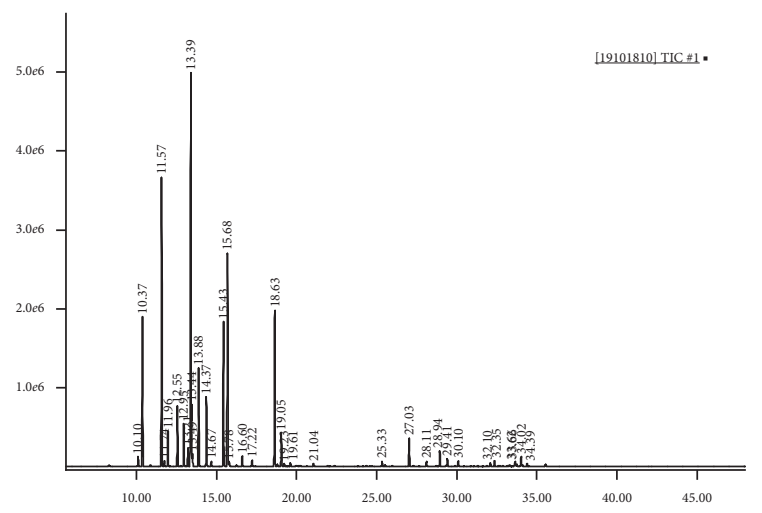

(a)

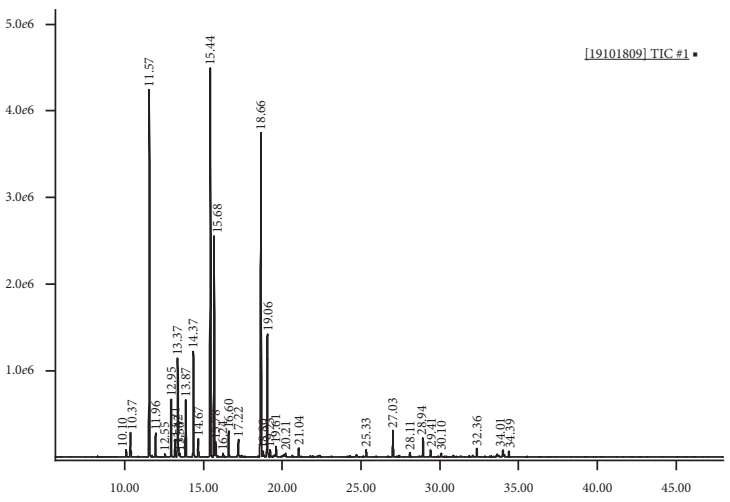

(c)

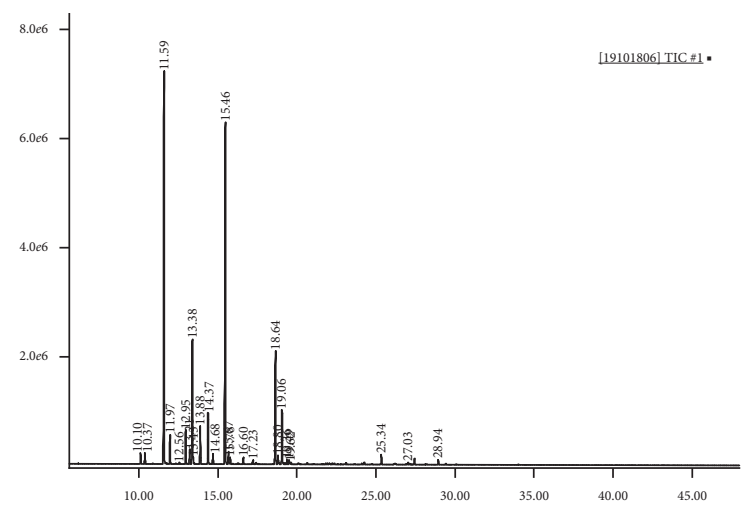

(e)

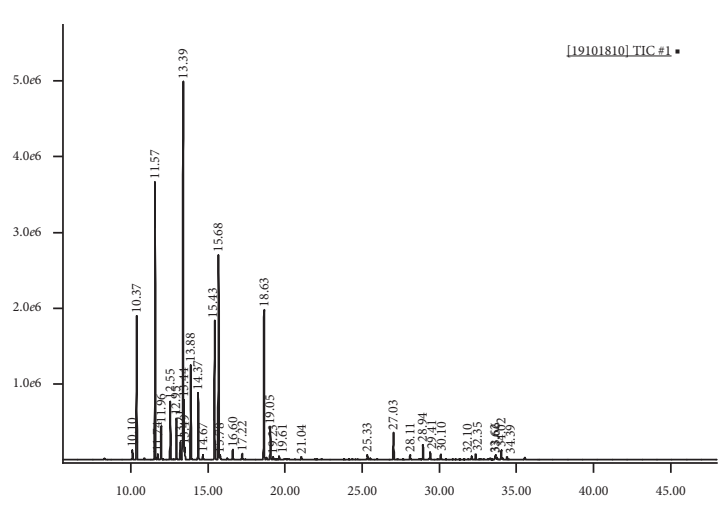

(b)

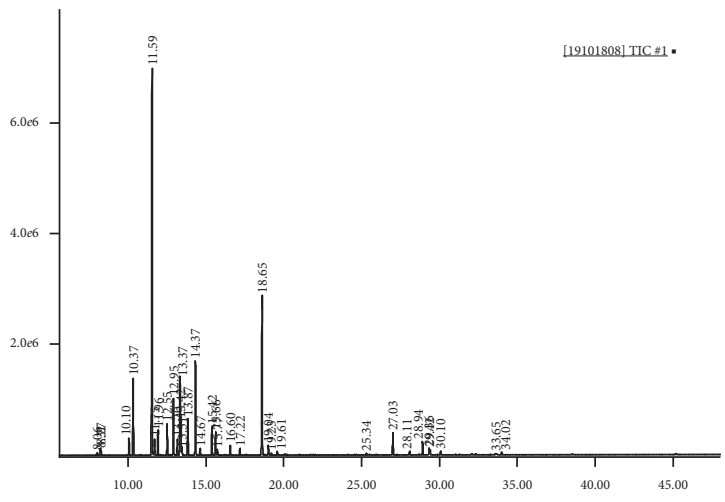

(d)

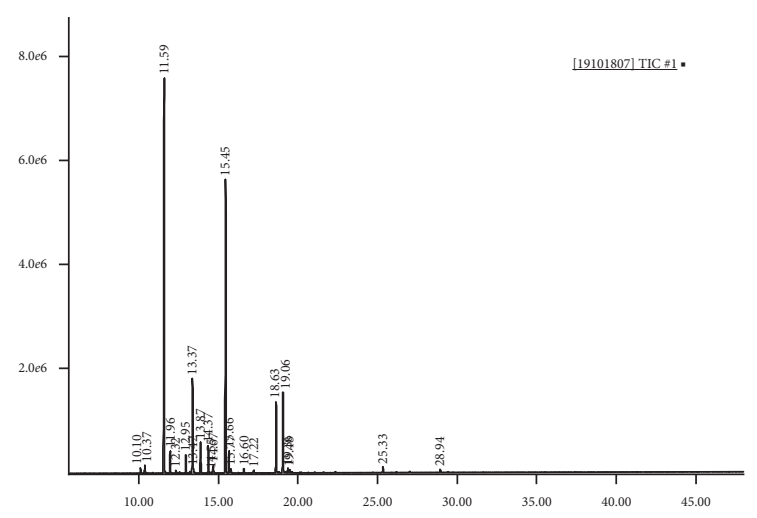

(f)

Figure 1: Chromatography of EOs from (a) SB, (b) LP, (c) FP, (d) FL, (e) DF, and (f) FF. 


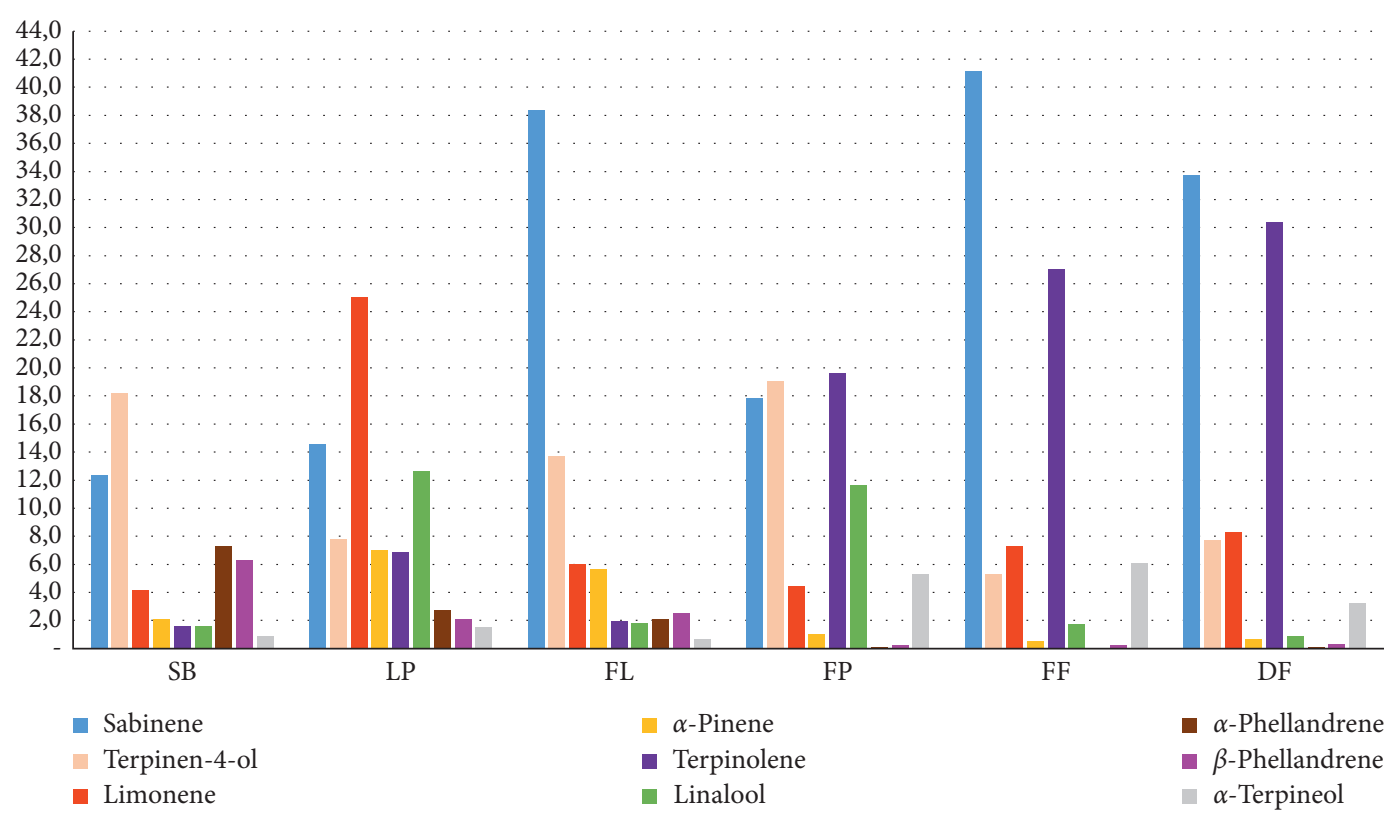

FIGURE 2: The main constituents in six essential oil samples.

intermedeol are present only in stem bark EO; trans-4,8dimethylnona-1,3,7-triene is present only in fruit petiole EO; (Z)-hex-3-en-1-ol, (Z)-hex-2-en-1-ol, $n$-hexanol, and (E,E)$\alpha$-farnesene are present only in fresh leaf EO; and the two compounds decanal and octyl acetate are specific to fresh and dried fruit EOs.

\subsection{Biological Activity of Z. rhetsa EOs}

3.2.1. Cytotoxicity. Six EO samples extracted from different parts of $Z$. rhetsa collected from the Son La province in Vietnam were tested for their cytotoxicity effect against five cancer cell lines (MCF-7, HeLa, HGC-27, Hep-G2, and A-549) and a normal cell line Vero. The cytotoxic activities were expressed by $\mathrm{IC}_{50}$ values, which revealed that all EOs at maximum concentration slightly inhibited at least one tested cell line $\left(\mathrm{IC}_{50}\right.$ ranges from 46.21 to $89.39 \mu \mathrm{g} / \mathrm{mL}$; Table 2 ).

Particularly, the EO of fresh leaves (FL) exhibited stronger cytotoxicity against four tested cancer cell lines, while the EO of stem bark (SB) and of fresh fruit (FF) exhibited cytotoxicity against HGC-27 and A-549, respectively. Significantly, these EOs demonstrated no cytotoxicity against the normal Vero cell line at the final concentration of samples up to $100 \mu \mathrm{g} / \mathrm{mL}$. Naik et al. suggested that the EO from $Z$. rhetsa fruits could inhibit the cell viability and proliferation of breast cancer [10]. It was found the EO obtained from dried fruits collected from Nan of Thailand exhibited inhibitory effect on the growth of human lung cancer cell line $(\mathrm{H} 460)$ with an $\mathrm{EC}_{50}$ value of $1.79 \mu \mathrm{L} / \mathrm{mL}$. Meanwhile, the dried $Z$. rhetsa fruits collected from some districts of Thailand (Nan, Phayao, and Chiang Rai) revealed a wide range of $\mathrm{EC}_{50}$ values from $2.03 \mu \mathrm{g} / \mathrm{mL}$ to $7.07 \mu \mathrm{g} / \mathrm{mL}$ against human lung cancer cells (MRC-5) [9].
TABle 2: Cytotoxic activity of essential oils.

\begin{tabular}{lcccccc}
\hline \multirow{2}{*}{ Samples } & \multicolumn{7}{c}{$\mathrm{IC}_{50}, \mu \mathrm{g} / \mathrm{mL}$} \\
& MCF-7 & Hela & HGC-27 & HepG-2 & A-549 & Vero \\
\hline SB & $>100$ & $>100$ & $\mathbf{8 3 . 4 8}$ & $>100$ & $>100$ & $>100$ \\
FL & $\mathbf{7 5 . 1 9}$ & $>100$ & $\mathbf{7 2 . 6 9}$ & $\mathbf{8 9 . 3 9}$ & $\mathbf{6 6 . 2 7}$ & $>100$ \\
LP & $\mathbf{4 6 . 2 1}$ & $>100$ & $>100$ & $\mathbf{5 4 . 6 7}$ & $\mathbf{5 6 . 8}$ & $>100$ \\
FP & $\mathbf{7 2 . 9 3}$ & $>100$ & $>100$ & $>100$ & $>100$ & $>100$ \\
FF & $>100$ & $>100$ & $>100$ & $>100$ & $\mathbf{7 4 . 8 2}$ & $>100$ \\
DF & $>100$ & $>100$ & $>100$ & $\mathbf{4 8 . 4 5}$ & $\mathbf{6 2 . 5 7}$ & $>100$ \\
Ellipticine & 0.42 & 0.36 & 0.51 & 0.34 & 0.35 & 1.84 \\
\hline
\end{tabular}

MCF-7: human breast adenocarcinoma cells; HeLa: cervical cancer cells; HGC-27: human stomach carcinoma cell; Hep-G2: hepatocellular carcinoma; A-549: human lung adenocarcinoma epithelial cells; Vero: kidney epithetical cells.

3.2.2. Antimicrobial Activity. Six EO samples from different parts of $Z$. rhetsa collected from the Son La province in Vietnam were also tested for their antimicrobial activities (Table 3). The results demonstrated that most of the EOs showed moderate antimicrobial activity against $F$. oxysporum yet did not inhibited bacteria B. subtilis and S. aureus.

Vanden Bergher and Vlietinck also observed various degrees of inhibition of the fresh leaf EO of Z. rhetsa at different concentrations against the test fungal isolates. The obtained results have shown that the concentration of $12.5 \%$ exhibited the highest activity against $A$. niger, A. fumigatus, A. flavus, and Penicillium italicum in agar dilution tests [19]. Pham et al. suggested that terpinen-4-ol that is the main active constituent in $Z$. rhetsa pericarp EOs had the ability to inhibit stomach and intestine diseases [11]. Some other studies have also shown that essential oils obtained from plants exhibited potential antibacterial and antifungal activities [20-22]. 
TABLe 3: Antimicrobial activities of essential oils.

\begin{tabular}{|c|c|c|c|c|c|c|}
\hline \multirow{2}{*}{ Samples } & \multicolumn{6}{|c|}{ Minimum inhibitory concentration $(\mathrm{MIC}, \mu \mathrm{g} / \mathrm{mL})^{*}$} \\
\hline & E. coli & P. aeruginosa & B. subtilis & S. aureus & A. niger & F. oxysporum \\
\hline SB & $>200$ & $>200$ & $>200$ & $>200$ & $>200$ & $>200$ \\
\hline FL & $>200$ & $>200$ & $>200$ & $>200$ & $>200$ & 100 \\
\hline LP & $>200$ & 100 & $>200$ & $>200$ & $>200$ & 100 \\
\hline $\mathrm{FP}$ & 50 & $>200$ & $>200$ & $>200$ & $>200$ & 200 \\
\hline $\mathrm{FF}$ & 100 & 200 & $>200$ & $>200$ & $>200$ & 100 \\
\hline DF & $>200$ & $>200$ & $>200$ & $>200$ & $>200$ & 200 \\
\hline
\end{tabular}

${ }^{*}$ The highest test concentration $200 \mu \mathrm{g} / \mathrm{mL}$.

\section{Conclusions}

Six EO samples were obtained by hydrodistillation from different parts of $Z$. rhetsa (e.g., stem barks, fresh leaves, leaf and fruit petioles, fresh and dried fruits) collected in the Son La province in Vietnam. Monoterpene hydrocarbons were found to be the predominant compound of all six EO samples, of which sabinene is one of the major components (from $12.37 \%$ to $41.13 \%$ ) followed by limonene (from $4.18 \%$ to $25.01 \%$ ). Oxygenated monoterpenes is present in quite high content in six EO samples, in which terpinen-4-ol was found to be the main compound of this fraction (from 5.35\% to $19.07 \%)$. Sesquiterpene hydrocarbons and oxygenated sesquiterpenes were present at a relatively high concentration in stem bark EO (12.61\% and 6.93\%, respectively) but only in a trace amount in other samples. Especially, aliphatic ketones were found only in stem bark EO (2.77\%) and completely absent in the remaining five EO samples. Some compounds were present in all six EO samples but at different concentrations, such as terpinolene is present in high content in dried fruits, fresh fruits, fruit petioles, and leaf petioles $(30.37 \%, 27.05 \%, 19.66 \%$, and $6.86 \%$, respectively) but is in low content in fresh leaves and stem barks $(1.91 \%$ and $1.57 \%$, respectively); linalool is present in relatively high content in leaf petioles and fruit petioles $(12.63 \%$ and $11.64 \%$, respectively), but it is only present in trace amounts in fresh leaves, fresh fruits, stem barks, and dried fruits $(1.80 \%, 1.71 \%, 1.61 \%$, and $0.84 \%$, respectively). The cytotoxicity results have shown that six EOs at a concentration of $50 \mu \mathrm{g} / \mathrm{mL}$ exhibited inhibitory activity against at least one tested cancer cell line but were nontoxic on Vero normal cells. For the antimicrobial activity, most EOs showed moderate inhibitory effect against $F$. oxysporum, yet no effects were observed against B. subtilis and S. aureus.

\section{Data Availability}

The data used to support the findings of this study are available from the corresponding author upon request.

\section{Conflicts of Interest}

The authors declare that they have no conflicts of interest.

\section{Acknowledgments}

This research was funded by the Vietnam Academy of Science and Technology (VAST) under grant number VAST04.06/20-21.

\section{References}

[1] R. P. Adams, Identification of Essential Oil Components by Gas Chromatography/Quadrupole Mass Spectroscopy, Allured Publishing Corporation, Carol Stream, IL, USA, 3rd edition, 2004.

[2] D. S. Cao and T. M. C. Nguyen, "Features of periods of mac khen Zanthoxylum rhetsa (Roxb. DC) in Son La," Journal of Science-Tay Bac University: Natural Science and Technology, vol. 2, pp. 9-105, 2015.

[3] H. N. Do, T. N. H. Tran, D. G. Vu et al., "Screening for antiproliferative and antimicrobial activity of total lipids of some marine invertebrates collected from Vietnam's north central coast," Vietnam Journal of Chemistry, vol. 55, no. 6E, pp. 124-130, 2017.

[4] T. L. Do, Vietnamese Medicinal Plants and Ingredients, Medical Publishing House, Hanoi, Vietnam, 2001.

[5] F. Hu, X.-F. Tu, K. Thakur et al., "Comparison of antifungal activity of essential oils from different plants against three fungi," Food and Chemical Toxicology, vol. 134, Article ID 110821, 2019.

[6] L. Jirovetz, G. Buchbauer, M. P. Shafi, and A. Saidutty, "Analysis of the aroma compounds of the essential oil of seeds of the spice plant Zanthoxylum rhetsa from southern India," Zeitschrift for Lebensmitteluntersuchung und -Forschung A, vol. 206, no. 3, pp. 228-229, 1998.

[7] W. A. König, D. Joulain, and D. H. Hochmuth, "Terpenoids library-terpenoids and related constituents of essential oils," 2018, https://massfinder.com/wiki/Terpenoids_Library.

[8] H. J. Kro, S. Das, and K. Tayung, "Fungi associated with contaminated stored grains and their biological control using Zanthoxylum rhetsa essential oil," International Journal of Advances in Agricultural Science and Technology, vol. 4, no. 11, pp. 10-26, 2017.

[9] T. Mosmann, "Rapid colorimetric assay for cellular growth and survival: application to proliferation and cytotoxicity assays," Journal of Immunological Methods, vol. 65, no. 1-2, pp. 55-63, 1983.

[10] R. R. Naik, A. K. Shakya, N. A. Khalaf, S. Abuhamdah, G. A. Oriquat, and A. Maraqa, "GC-MS analysis and biological evaluation of essential oil of Zanthoxylum rhesta 
(Roxb.) DC pericarp," Jordan Journal of Pharmaceutical Sciences, vol. 8, no. 3, pp. 181-193, 2015.

[11] D. T. Pham, "Indigenous knowledge from the use of Mac Khen plant products (Zanthoxylum rhetsa (Roxb.) DC.) of Thai community in Son La," Journal of Science-Tay Bac University: Natural Science and Technology, vol. 14, pp. 90-96, 2018.

[12] R. P. Adams, Identification of Essential Oils by Ion Trap Mass Spectroscopy, Academic Press, San Diego, CA, USA, 1990.

[13] V. S. Rana and M. A. Blazquez, "Volatile constituents of the seed coat of Zanthoxylum rhetsa (Roxb.) DC," Journal of Essential Oil Research, vol. 22, no. 5, pp. 430-432, 2010.

[14] P. M. Shafi, B. Jose, K. T. Radhamani, and R. A. Clery, "Influence of $\mathrm{pH}$ on essential oil composition of Zanthoxylum rhetsa seeds obtained by steam distillation," Flavour and Fragrance Journal, vol. 21, no. 2, pp. 317-318, 2006.

[15] P. M. Shafi, A. Saidutty, and R. A. Clery, "Volatile constituents of Zanthoxylum rhetsa leaves and seeds," Journal of Essential Oil Research, vol. 12, no. 2, pp. 179-182, 2000.

[16] S. Theeramunkong and M. Utsintong, "Comparison between volatile oil from fresh and dried fruits of Zanthoxylum rhetsa (Roxb.) DC. and cytotoxicity activity evaluation," Pharmacognosy Journal, vol. 10, no. 5, pp. 827-832, 2018.

[17] H. T. Tran, M. H. Tran, and Q. H. Nguyen, "Chemical components of essential oil extracted from fruit of Zanthoxylum rhetsa (Roxb.) DC in Vietnam," Journal of Pharmacology, vol. 10, pp. 12-13, 2004.

[18] X.-F. Tu, F. Hu, K. Thakur, X.-L. Li, Y.-S. Zhang, and Z.-J. Wei, "Comparison of antibacterial effects and fumigant toxicity of essential oils extracted from different plants," Industrial Crops and Products, vol. 124, pp. 192-200, 2018.

[19] D. A. Vanden Bergher and A. J. Vlietinck, "Screening methods of antibacterial and antiviral agents from higher plants," in Methods in Plant Biochemistry, P. M. Dey and J. D. Harbone, Eds., pp. 47-69, Academic Press, London, UK, 1991.

[20] V. C. Vu, Dictionary of Vietnamese Medicinal Plants, pp. 622-623, Medical Publishing House, Hanoi, Vietnam, 1997.

[21] X. Wang, Y. Shen, K. Thakur et al., "Antibacterial activity and mechanism of ginger essential oil against Escherichia coli and Staphylococcus aureus," Molecules, vol. 25, no. 17, p. 3955, 2020.

[22] N. Wongkattiya, C. Akekawatchai, P. Sanguansermsri, I. H. Fraser, C. Pratoomsoot, and D. Sanguansermsr, "Chemical compositions and biological properties of essential oils from Zanthoxylum rhetsa (Roxb.) DC and Zanthoxylum limonella Alston," African Journal of Traditional, Complementary and Alternative Medicines, vol. 15, no. 2, pp. 12-18, 2018. 